Est Ag 39 (2004) 5-31

\title{
Identidad e iniciación cristiana (II)
}

\section{II.- LA INICIACIÓN CRISTIANA CLÁSICA}

A estas alturas de nuestro trabajo, consideramos que es oportuno delimitar lo que se puede entender por "iniciación cristiana" para no reducirla a los aspectos litúrgicos ni a los catequéticos, pues cualquiera de los dos sería parcial y restrictivo ${ }^{1}$.

"En general, 'iniciación cristiana' es aquel proceso por el que una persona es introducida al misterio de Cristo y a la vida de la Iglesia, a través de unas mediaciones sacramentales y extrasacramentales, que van acompañando el cambio de su actitud fundamental, de su ser y existir con los demás y en el mundo, de su nueva identidad como persona cristiana creyente."2.

El Catecismo de la Iglesia Católica en el epígrafe sobre "La iniciación cristiana" afirma:

"Desde los tiempos apostólicos, para llegar a ser cristiano se sigue un camino y una iniciación que consta de varias etapas. Este camino puede ser recorrido rápida o lentamente. $Y$ comprende siempre algunos elementos esenciales: el anuncio de la Palabra, la acogida del Evangelio que lleva a la conversión, la profesión de fe, el Bautismo, la efusión del Espíritu Santo, el acceso a la comunión eucarística." (CCE 1229)

1. "Por tanto, la Iniciación no consiste sólo en la celebración de los sacramentos del Bautismo, la Confirmación y la primera Eucaristía, aunque estos momentos rituales constituyen de hecho la cumbre de todo el proceso. La Iniciación tampoco se reduce a la catequesis general y a las catequesis presacramentales. Es decir, no es un mero programa educativo de la fe ni una preparación para el compromiso cristiano, ni siquiera en el caso de los adultos en proceso de redescubrimiento o de maduración de su fe. La Iniciación cristiana comprende a la vez todos los aspectos señalados, conectados entre sí." J. López, La iniciación cristiana, inserción en Jesucristo y en la vida de la Iglesia, en Phase 218 (1997) 121.

2. D. Borobio, La iniciación cristiana, 33. "El ritual no presenta solamente la celebración de los sacramentos del bautismo, la confirmación y la eucaristía, sino también todos los ritos del catecumenado [...]" (RICA 2). 
El reciente documento de la Conferencia Episcopal Española dedicado al tema que nos ocupa se afirma:

"La Iniciación cristiana es la inserción de un candidato en el misterio de Cristo, muerto y resucitado, y en la Iglesia por medio de la fe y de los sacramentos. [...] Esta inserción en el misterio de Cristo va unida a un itinerario catequético que ayuda a crecer y a madurar la vida de fe. En efecto, 'la catequesis es elemento fundamental de la Iniciación cristiana y está estrechamente vinculada a los sacramentos de la iniciación'." (IC 19-20)

No queremos prodigar las referencias a lo que se entiende por 'iniciación cristiana', pero consideramos que las mejores aproximaciones a una definición de la misma son deudoras del documento AG 14 cuando, hablando de los que han recibido la fe en Cristo por medio de la Iglesia, dice que deben ser admitidos al catecumenado, que es "una formación y noviciado convenientemente prolongado de la vida cristiana", para que se unan más a Cristo $^{3}$. Y sigue afirmando:

"Iníciense, pues, los catecúmenos convenientemente en el misterio de la salvación, en el ejercicio de las costumbres evangélicas y en los ritos sagrados que han de celebrarse en los tiempos sucesivos, y sean introducidos en la vida de fe, de liturgia y de caridad del pueblo de Dios."

La fe cristiana no se demuestra, se muestra; no se impone, se propone. Los que la aceptan como gracia han de comenzar un proceso eclesial para hacerla madurar. En cuanto que la fe tiene una estructura simbólica y sacramental, necesita de la Iglesia como sacramento de Cristo, para alcanzar su plenitud.

"Hablar de iniciación en el cristianismo es, pues, tratar de la manera por la que un individuo en su marco determinado, con un apoyo apropiado y a través de medios propios adquiere la identidad cristiana que se interioriza verdaderamente como un don del Señor"4.

Por el hecho de que los marcos culturales van cambiando a lo largo del tiempo y del espacio, los medios propios de la iniciación habrán de cambiar

3. "Recobrar el sentido de los sacramentos de iniciación y de la iniciación cristiana es tarea ineludible para la presencia en el mundo de una Iglesia con identidad. No hay identidad cristiana sin los sacramentos de iniciación. Y éstos reclaman el catecumenado." A. CAÑIZARES LlOVERA, Los sacramentos de iniciación cristiana, en Teología y Catequesis 28 (1988) 642.

4. A. Ginel VIELVA, La iniciación cristiana como lugar especial de la formación del lenguaje religioso, en Teología y Catequesis 4 (1982) 515. 
para conseguir su objetivo permanente: adquirir la identidad cristiana. En los dos apartados siguientes vamos a intentar poner de manifiesto las etapas del catecumenado antiguo así como algunos elementos importantes de su liminaridad.

\section{1.- Etapas de la iniciación cristiana antigua ${ }^{5}$}

De sobra conocido es que el catecumenado clásico no fue uniforme en las diferentes iglesias locales. Con todo, vamos a tratar de descubrir la estructura profunda de la iniciación cristiana que sí creemos permaneció constante en los periodos en los que esta se llevó a cabo antes de que el estado de cristiandad se implantase definitivamente. ${ }^{6}$ A pesar de los profundos cambios históricos así como de las diferencias locales, creemos que tanto las etapas fundamentales como los objetivos de la iniciación cristiana fueron similares en las distintas iglesias a partir del siglo II. Para descubrir la estructura profunda a la que hemos hecho referencia, vamos a servirnos fundamentalmente de dos guías privilegiados: Hipólito de Roma y Agustín de Hipona7. Estos autores testimonian dos momentos históricos diferentes en la iniciación cristiana: el primero lo hace cuando el cristianismo es una religión más, aunque minoritaria, dentro de la cuenca mediterránea, en medio de persecuciones intermitentes y teniendo que afrontar el problema de los lapsi; el segundo, por el contrario, cuando el cristianismo se ha convertido en la religión oficial del Imperio Romano con todo lo que lleva consigo de seguridad para la Iglesia, de privilegios para sus miembros y de tensiones herético-cismáticas en su seno. Si en el primer caso la iniciación trataba de asegurar y hacer madurar la conversión inicial que se había produ-

5. Una aportación breve pero densa en contenido respecto al proceso de iniciación cristiana en las diferentes Iglesias a lo largo del tiempo, así como las etapas que lo conformaban lo tenemos en M. DuJARIER, Breve historia del catecumenado, Descleé de Brouwer, Bilbao 1986, 37-124. Para un breve resumen de las etapas y elementos esenciales del catecumenado antiguo cf. J. DANIELOU - R. DU CHARLAT, La catequesis en los primeros siglos, Studium, Madrid 1975, 37-59.

6. Cf. G. GropPo, Catecumenado antiguo, en J. Gevaert (dir.), Diccionario de catequética, CCS, Madrid 1987, 146. "Sin querer forzar el valor probativo de cada texto, que habría que precisar según su origen, se desprende, con todo, de todos estos escritos populares una convicción de conjunto: en el siglo III, la práctica catecumenal presenta por todas parte la misma estructura." M. DUJARIER, Breve historia del catecumenado, 78. La cursiva es nuestra.

7. El mejor, más profundo y completo estudio del proceso de iniciación cristiana según San Agustín al que hemos accedido es el de W. HARMLEss, Augustine and the Catechumenate, The Liturgical Press, Collegeville 1995. 
cido por la primera evangelización para que el candidato permaneciera fiel en la Iglesia dentro de un contexto social adverso, en el segundo el proceso de iniciación se había reducido considerablemente al tiempo de la cuaresma y pretendía llamar a la conversión a los que pedían el acceso a la Iglesia por motivaciones no siempre relativas a la fe. En la primera etapa, la conversión y el crecimiento en la fe eran sellados con los sacramentos de iniciación cristiana; en la segunda, los sacramentos empezaban a recibirse sin que la fe y la conversión estuvieran aseguradas 8 .

La sociedad del Imperio Romano constituía un serio obstáculo para acceder a la vida cristiana. Hasta el 313 la Iglesia vivió una situación difícil en medio de un ambiente hostil y de persecuciones intermitentes. Este contexto hace insistir en la exigencia para la admisión de candidatos y la misión. Como consecuencia, la Iglesia tuvo que organizar un tiempo de prueba e iniciación cuyo desarrollo progresivo cristalizó en la estructuración del catecumenado 9 . La preparación y el discernimiento se hacían de manera seria y exigente utilizando para ello un período de tiempo suficientemente prolongado con el fin de consolidar una conversión sincera que transformase la totalidad de la vida de los que pedían hacerse cristianos. La estructura profunda del catecumenado clásico estaba determinada por la ordenación de los diferentes elementos que lo componían para conseguir su finalidad propia. Pese a que el catecumenado varía de unas iglesias a otras, podemos basarnos en la segunda parte de la Tradición Apostólica de Hipólito (nn. 15-21) para descubrir algunas de las claves y constantes del catecumenado antiguo ${ }^{10}$.

8. Cf. M. DuJARIER, Breve historia del catecumenado, 115-117; A. López CALvo, La iniciación cristiana: una problemática actual, en Teología y Catequesis 72 (1999) 12.

9. "Se entiende por catecumenado (de katejein = instruir de palabra), en sentido más clásico, la instrucción iniciática de carácter catequético-litúrgico-moral, creada por la Iglesia de los primeros siglos, con el fin de preparar y conducir a los convertidos adultos, a través de un proceso espaciado y dividido por etapas, al encuentro pleno con el misterio de Cristo y con la vida de la comunidad eclesial, expresado en su momento culminante por los ritos bautismales de iniciación: bautismo, ritos posbautismales, eucaristía, que normalmente presididos por el obispo, se celebran en la vigilia pascual." D. BOROBIO, Catecumenado, en C. Floristan - J. J. Tamayo (eds.), Conceptos fundamentales del cristianismo, Trotta, Madrid 1993, 131.

10. Cf. J. DANiElou - R. Du Charlat, La catequesis en los primeros siglos, 28-29. "Es en el siglo III cuando el itinerario hacia el bautismo es más exigente y está mejor estructurado. Lo que Hipólito de Roma dice de él ya lo pone de manifiesto. Pero los historiadores no han mostrado aún suficientemente que la práctica de Hipólito, lejos de ser una afortunada excepción, refleja en realidad la manera habitual de hacer de las diferentes Iglesias esparcidas por el mundo mediterráneo." M. DUJARIER, Breve historia del catecumenado, 132. Para la misma idea cf. ib. 62. No es de la misma opinión A. NOCENT, Iniciación cristia- 
Como institución iniciática eclesial, el catecumenado es el conjunto de instrucciones, símbolos y ritos de paso utilizados por la Iglesia para instruir, acompañar y llevar a cabo, con el que no es un miembro de la comunidad, la transición entre su estado previo -pagano- y el estado final -fiel cristiano- como miembro de pleno derecho integrado en la comunidad cristiana. Al ser una institución iniciática participa del mismo esquema trifásico de los ritos de paso: separación, margen (o limen) y agregación.

\begin{tabular}{|c|c|c|}
\hline Separación & Margen (o limen) & Agregación \\
\hline $\begin{array}{l}\text { Supone, por parte del } \\
\text { aspirante, un interés inicial } \\
\text { por ser cristiano y una sepa- } \\
\text { ración del modo de vida } \\
\text { previo que hasta entonces } \\
\text { estaba llevando. } \\
\text { El aspirante ha de dar } \\
\text { muestras de una primera } \\
\text { conversión y de una fe ini- } \\
\text { cial. Se le somete a un pri- } \\
\text { mer examen para consta- } \\
\text { tar si se ha dado y si se ha } \\
\text { separado de su antigua con- } \\
\text { ducta. }\end{array}$ & $\begin{array}{l}\text { El estado del catecú- } \\
\text { meno es ambiguo, aunque } \\
\text { ha de clarificarse progresi- } \\
\text { vamente al ir avanzando } \\
\text { por las sucesivas etapas del } \\
\text { catecumenado hasta madu- } \\
\text { rar su primera conversión. } \\
\text { El catecúmeno es un } \\
\text { 'pasajero' que está en cami- } \\
\text { no de convertirse en cristia- } \\
\text { no aunque todavía no lo } \\
\text { sea11. Por ello, no puede aún } \\
\text { participar plenamente de la } \\
\text { asamblea litúrgico-eucarísti- } \\
\text { ca12. Al mismo tiempo no } \\
\text { puede llevar la vida del } \\
\text { pagano que era antes pues } \\
\text { se está entrenando para } \\
\text { renunciar al pecado y adhe- } \\
\text { rirse plenamente a Cristo. } \\
\text { El catecúmeno es una } \\
\text { especie de embrión que está } \\
\text { siendo gestado en el seno } \\
\text { de la Iglesia mediante sus } \\
\text { cuidados y solicitudi3. }\end{array}$ & $\begin{array}{l}\text { El elegido, a través de } \\
\text { los sacramentos de inicia- } \\
\text { ción, alcanza un nuevo esta- } \\
\text { do (hijo adoptivo de Dios, } \\
\text { miembro pleno de la Igle- } \\
\text { sia...) y por ello adquiere } \\
\text { derechos y obligaciones en } \\
\text { la nueva comunidad a la que } \\
\text { es agregado. } \\
\text { Su nuevo estado está } \\
\text { claramente definido, en con- } \\
\text { traste con la etapa anterior. } \\
\text { La Iglesia en la que ha } \\
\text { sido iniciado espera del } \\
\text { nuevo miembro que profe- } \\
\text { se su misma fe y se compor- } \\
\text { te de acuerdo con ciertas } \\
\text { normas y patrones éticos } \\
\text { inspirados en el Evangelio } \\
\text { como discípulo de Cristo y } \\
\text { en comunión con la Iglesia. }\end{array}$ \\
\hline
\end{tabular}

na, en D. Sartore - A. M. Triacca (dir.), Nuevo Diccionario de Liturgia, Paulinas, Madrid 1987, 1054. Para una breve exposición de la evolución de la iniciación cristiana en la Iglesia postapostólica cf. M. A. MEDINA, La iniciación como proceso de madurez socio-religiosa. Breve recorrido por la historia, en Teología y Catequesis 72 (1999) 27-35.

11. "Los catecúmenos llevan la señal de la cruz en la frente: son ya de la casa grande; sólo les falta que de esclavos pasen a ser hijos; ya son algo, ya son de la casa grande." (SAN Agustín, In Joh. 11,4).

12. "Se dice al catecúmeno: ¿Crees en Cristo? Y él contesta: Sí, creo, y se hace la señal de la cruz; lleva ya en la frente la cruz de Cristo y no se ruboriza de la cruz de su Señor. Esta es la señal de que creyó en su nombre. Hagámosle otra pregunta: ¿Comes la carne y bebes la sangre del Hijo del hombre? No entiende lo que le decimos: es que Jesús aún no se ha confiado o entregado a él." (SAN AGUSTín, In Joh. 11,3)

13. Cf. SAN Agustín, In Joh. 12,3. 
La iniciación cristiana estaba compuesta por cuatro etapas de duración desigual: $1^{\mathrm{a}}$ pre-catecumenado, $2^{\mathrm{a}}$ catecumenado, $3^{\mathrm{a}}$ preparación próxima $y$ celebración de los sacramentos de iniciación, $4^{\mathrm{a}}$ mistagógica, etapas que básicamente se van a volver a repetir en nuestros días en el RICA $^{14}$.

\begin{tabular}{|l|l|l|}
\cline { 2 - 3 } \multicolumn{1}{c|}{} & \multicolumn{2}{c|}{ denominación } \\
\hline Etapas & en Oriente & en Occidente \\
\hline acercamiento inicial & & accedentes, venientes, rudes \\
\hline preparación remota & atechoumenoi & audientes \\
\hline preparación próxima al bautismo & photizomenoi & electi, competetens \\
\hline
\end{tabular}

\section{a) 'Pre-catecumenado'}

Hipólito no nos informa respecto a esta primera etapa aunque sí otros autores. ${ }^{15} \mathrm{El}$ pre-catecumenado no tenía una duración limitada y era, por así decirlo, una evangelización no sistemática llevada a cabo por los cristianos en sus ambientes. ${ }^{16}$ Mediante un anuncio kerigmático, poniendo de manifiesto la fe y vida cristiana en contraposición por una parte con los de fuera -judíos, paganos y herejes-y por otra con de dentro -cristianos que no viven de acuerdo con su nueva condición-. ${ }^{17} \mathrm{El}$ objetivo de esta etapa era despertar el interés y una primera conversión en el destinatario que muestra un cierto interés por el cristianismo. ${ }^{18}$ "Los que se presentaban como

14. Para la tabla que sigue cf. J. DANielou - R. Du Charlat, La catequesis en los primeros siglos, 38-39; L. RESINES, El catecumenado en "De catechizandis rudibus", en Estudio Agustiniano 22 (1987) 373-374; J. OROZ RETA, Introducción a "De catechizandis rudibus", en San Agustín, Obras completas XXXIX, BAC, Madrid 1988, 425-427.

15. Cf. M. DujARIER, Breve historia del catecumenado, 68-69. "Si deseas alcanzar tú también esa fe, trata de adquirir conocimiento del Padre." (Cf. Discurso a Diogneto X, 1). Aunque, por una parte, el Discurso a Diogneto puede encuadrarse dentro de la apología, por otra, puede también considerarse como una primera presentación del mensaje cristiano destinado a los que son precatecúmenos. El De catechizandis rudibus es la obra que mejor nos ilustra el período previo al catecumenado.

16. Para una sugerente exposición sobre lo que motivaba el interés inicial por el cristianismo en el período que va desde finales del siglo I a comienzos del IV cf. F. J. MARTíNEZ, Iniciación y catequesis en la Iglesia antigua: apuntes marginales, en Teología y Catequesis 4 (1984) 535-550.

17. Cf. Discurso a Diogneto II-IV; SAn Agustín, De cat. rud., VII, 11; XXVII, 55.

18. Cf. Discurso a Diogneto I-II,1. 
candidatos al bautismo y accedían, por tanto a la instrucción cristiana habían dado ya un paso previo: interesarse por la nueva fe. La magnitud de este paso, las rupturas con todo un mundo de prejuicios y de actitudes espontáneas que implicaba, es algo que tal vez nos resulta hoy difícil imaginar"19.

Para acceder al catecumenado (= ser 'oyente de la palabra') se requería pasar un examen de ingreso previo: ${ }^{20}$ Los postulantes debían presentarse ante los doctores y ser interrogados por ellos sobre las razones y motivos que les condujeron a la fe y sobre su estado de vida. Los fieles que hicieron la primera evangelización, generalmente laicos, eran interrogados sobre la capacidad de los presentados "para escuchar la palabra" (Trad. Apost. 15). Ellos eran sus garantes ante la comunidad. En el examen se interrogaba también sobre el oficio del candidato, ya que había profesiones y oficios que la comunidad consideraba incompatibles con el ser cristiano (regente de una casa de prostitución, escultor o pintor que fabrique ídolos, actor de teatro, auriga, gladiador o cualquier otra ocupación vinculada a los juegos, sacerdote pagano, magistrado, mago, astrólogo, adivinador...) por implicar idolatría o ir contra la moral cristiana. Hipólito, en la enumeración que hace, no trataba de agotar todas las profesiones indignas del cristiano, sino que otras muchas las deja para que sean discernidas por la comunidad guiada por el Espíritu. ${ }^{21} \mathrm{El}$ primer escrutinio se hacía antes de que lleguen los fieles $^{22}$ pues parece que también ellos participaban, al menos con su presencia, de la mayor parte del proceso de iniciación. ${ }^{23}$

Con este primer escrutinio la comunidad cristiana pretende poner de manifiesto y constatar que la primera fase de la iniciación se ha llevado a cabo, es decir, que se ha producido una primera separación respecto a talantes y conductas incompatibles con los valores y sentidos compartidos en la comunidad cristiana. Este primer examen trata sobre las intenciones y disposiciones del candidato. ${ }^{24}$ No era suficiente la mera respuesta del candidato

19. F. J. MARTÍNEZ, Iniciación y catequesis en la Iglesia antigua: apuntes marginales, 536.

20. Cf. G. Groppo, Catecumenado antiguo, 147.

21. "Si hemos omitido algo, las profesiones mismas os instruirán, ya que todos tenemos el Espíritu de Dios." (Trad. Apost. 16). Cf. SAN Agustín, De fide et op. XVIII, 33.

22. Cf. Trad. Apost. 15.

23. Cf. Trad. Apost. 35.

24. "La finalidad de estas [...] preguntas es establecer si existen las condiciones objetivas, tanto para la escucha fructífera de la catequesis como para el cumplimiento de los compromisos éticos, que dimanan de la fe." (G. GropPo, Catecumenado antiguo, 147). Respecto al uso que Orígenes hacía del pacto de Siquém (Jos 24, 14-24) Dujarier afirma: "El principio de la catequesis supone, por lo tanto, para el oyente, un acontecimiento análogo al de Siquém. Por eso la aplicación de este texto a los catecúmenos es perfectamente pertinente 
sobre su propia intención, sino que se necesita el aval tanto de la propia vida como la de un garante que, habiéndole acompañado en su decisión, testificase en su favor asegurando la rectitud de dicha intención. La comunidad quería estar segura de que los candidatos tenían capacidad para 'escuchar', pues consideraba que no todos, debido a sus condiciones de vida objetivas, tenían el oído abierto para entender. Este 'entendimiento' estaría abierto si se había producido la conversión inicial, de lo contrario nada de lo que oyeran les cambiaría la vida. Lógicamente, los garantes o padrinos deberían de ser fieles de la propia comunidad. El aval de la propia vida debía dar pruebas claras y, hasta cierto punto, objetivas de que el candidato se había separado de un modo de vida previo contrario al Evangelio. Si esta separación no era constatada por parte de la comunidad, el candidato no era considerado idóneo para continuar la iniciación debido a que las condiciones objetivas en su forma de vida van a impedir la progresión e introducción del candidato en la fase siguiente. Un candidato que no rompiese con las estructuras vitales previas se consideraba incapacitado para ser introducido o iniciado en la vida diferente inaugurada por el misterio pascual de Cristo. Dicho de otro modo, un sujeto que no 'muriese' no podía aspirar a 'resucitar'.

A partir del 313 la situación social en la que vive la Iglesia cambia. De ser una religión marginal, se irá convirtiendo en la religión del Imperio. Ante la nueva situación surgieron nuevos problemas y se intentaron buscaron nuevas soluciones. ${ }^{25} \mathrm{El}$ número de los que pedían el bautismo creció, aunque no siempre sus motivos fueran sinceros. La mayor facilidad para entrar en la Iglesia y las posibles ventajas que ello podía suponer hacían que la petición de entrada tuviera, en muchos casos, motivaciones bastardas. Los padres afirmaron la necesidad de investigar y discernir los verdaderos motivos del postulante para, en caso necesario, purificarlos. ${ }^{26}$ Con todo, poco a poco, el examen de ingreso al catecumenado fue perdiendo importancia hasta convertirse en un acto formal de dar el nombre para recibir los sacramentos. Con todo, se conserva en el siglo $\mathrm{V}$ un testimonio de lo que podría ser el ingreso en el catecumenado que consistiría básicamente en preguntar al candidato si cree en los enunciados básicos de la fe católica, la signación solemne y el rito de la sal. ${ }^{27}$

y la manera como Orígenes les enseña a leer su experiencia en la Palabra misma de Dios es admirable." M. DUJARIER, Breve historia del catecumenado, 70.

25. Cf. L. RESINES, El catecumenado en "De catechizandis rudibus", 377-381.

26. Cf. SAn Cirilo de Jerusalén, Procat. 5; SAn Agustín, De cat. rud. V, 9; VI, 10; XVII, 26; M. DUJARIER, Breve historia del catecumenado, 84-86.

27. Cf. SAN Agustín, De cat. rud. XXVI, 50. 
La iniciación cristiana no comienza con el catecumenado sino cuando en una persona, al entrar en contacto con la Iglesia -con los cristianos concretos-, surge la curiosidad, la pregunta por el comportamiento diferente que percibe y que, a su vez, remite a un sentido de vida también distinto. El precatecumenado comienza cuando la fe de la Iglesia, por ser esencialmente sacramental -en el sentido profundo y amplio del término- es percibida de manera concreta en gestos de esperanza o caridad por un no creyente. Normalmente, la Iglesia se hace presente mediante sus miembros en los diferentes ámbitos de la existencia cotidiana.

“[...] el cristianismo es fundamentalmente un seguimiento. Alguien se pone en movimiento porque percibe en la vida de otros hombres una realidad - no expresable tal vez- que merece ser seguida. Naturalmente, para que el encuentro se produzca se requieren determinadas condiciones por parte de la acción del creyente. Esa acción tiene que ser gratuita, inexplicable desde la sabiduría de este mundo, tiene que llevar el sello de la necedad de la cruz. De otro modo no hay extrañeza, y sin extrañeza no hay pregunta. [...] la conducta del creyente remite necesariamente a una realidad que está más allá, y que es justamente lo que la hace posible. Remite, en primer lugar, a la Iglesia. Lo que el cristiano vive -la fe, la esperanza y la caridad, que es, en definitiva, lo que ofrece a los otros-, lo vive en tanto que cristiano, en tanto que miembro de la Iglesia. La forma de vivirlo es hacerse cristiano, incorporarse a la comunión de la Iglesia. Pero ni siquiera ésta es la referencia última. La referencia última, lo que convierte la necedad en sabiduría [...] es la locura de la cruz, es el hecho de Jesucristo. Ha habido, en la historia humana, un acontecimiento, de alcance universal, que no sólo desvela de forma adorable la divinidad ('Dios es amor'), sino que transforma de cuajo el significado de la historia y de la vida de los hombres. Desde ahí -y sólo desde ahí- se explica la absurda conducta de los cristianos" 28 .

Después de que la sinagoga se cerró como medio para la misión (cf. Jn 9,22 ), y dado que los foros públicos les eran hostiles, los cristianos tuvieron que ejercer la misión en los ámbitos cotidianos (la calle, el trabaj̣c, las relaciones humanas...). ${ }^{29}$ La dinámica esencialmente sacramental de fe está en el origen de la misma: la auténtica vida de fe de un cristiano es sacramental y remite, necesariamente, a la sacramentalidad más amplia de la Iglesia que, a su vez, trasluce la presencia de Jesucristo, sacramento del Padre. La ecle549.

28. F. J. MARTíNeZ, Iniciación y catequesis en la Iglesia antigua: apuntes marginales,

29. Cf. F. J. MARTÍNEZ, Iniciación y catequesis en la Iglesia antigua: apuntes marginales, 543. 
sialidad, la sacramentalidad y la misión de la vida cristiana -determinadas por la fe, la esperanza y la caridad-se implican y reclaman mutuamente ${ }^{30}$.

“ [...] en la Iglesia antigua nadie se sentía excluido del mandato del Señor: 'Id a todo el mundo y proclamad la Buena Nueva a toda la creación' (Mc 15,15). La sensibilidad hacia la misión es previa e independiente del lugar que se ocupa en la comunidad cristiana. No es tampoco una especie de 'añadido' a la vocación cristiana, sino un componente esencial del hecho de ser miembro de la Iglesia"31.

El testimonio de una vida moral elevada, que contrastaba con la del entorno social, junto con la fortaleza a la hora de afrontar el martirio, confería autoridad y credibilidad a personas humildes, sin formación académica, que se apoyaban exclusivamente sobre la fe en Cristo. El testimonio de esta fe profunda es lo que constituye la clave de la misión y el punto de partida de la pregunta del no creyente.32 Para Paul Tillich "Es el testimonio silencioso de la comunidad de fe y amor lo que convence al que pregunta, el cual puede ser silenciado pero jamás convencido por los argumentos más incontrovertibles." 33 De esta manera, la misión es al mismo tiempo, comienzo de la preliminaridad iniciática y uno de los signos que verifican que la iniciación cristiana ha llegado a cumplir su objetivo.

"[...] el que ha sido evangelizado evangeliza a su vez. He ahí la prueba de la verdad, la piedra de toque de la evangelización: es impensable que un hombre haya acogido la Palabra y se haya entregado al Reino sin convertirse en alguien que a su vez da testimonio y anuncia." (EN 24).

La etapa preliminar de la iniciación cristiana acaba cuando el que ha recibido el testimonio cristiano se siente interpelado en su vida, accede a la fe inicial y manifiesta su interés por convertirse. En otras palabras: cuando el destinatario descubre gozosamente que el Evangelio encarnado por el testigo eclesial puede ser el sentido que oriente su vida y está dispuesto a

30. "El punto original del que se ha de partir para una determinación del acto de fe y de toda relación con Dios en una teología cristiana no es, en efecto, formalmente expresado, una relación sujeto-objeto, sino una relación sujeto-sujeto, el yo-tú del amor fraterno realizado o rehusado." J. B. METZ, La incredulidad como problema teológico, en Concilium 6 (1965) 78.

31. F. J. MARTíNEZ, Iniciación y catequesis en la Iglesia antigua: apuntes marginales, 542. Cf. EN 59-60.

32. Cf. EN 21; 42-43; 46.

33. Citado por A. GARrido, La Iglesia en el pensamiento de Paul Tillich, Sígueme, Salamanca 1979, 250. 
recorrer el proceso que le afiance ese descubrimiento, se encuentra ante el primer umbral o grado de la iniciación cristiana, es decir, ante el acceso a la etapa liminar o catecumenado.

\section{b) Catecumenado}

El catecumenado es, hablando con propiedad, la segunda fase de la iniciación cristiana y se corresponde a la fase o periodo liminar de los ritos de paso. Según la Tradición Apostólica, el catecumenado consistía en la instrucción oral durante tres años llevada a cabo por los 'doctores' que podían ser clérigos o laicos. ${ }^{34} \mathrm{El}$ objetivo de estas catequesis no era tanto la instrucción intelectual, como se ve bien por la cláusula de excepción, ${ }^{35}$ sino la maduración de la opción de fe tomada a raíz de la etapa anterior y el hacerla verdad en la propia vida del catecúmeno. ${ }^{36}$

Un factor que se introduce a partir del siglo IV digno de ser mencionado es la práctica habitual, entre muchos que comenzaban el catecumenado, que dilataban el mismo durante años sin dar el paso hacia los sacramentos de iniciación. En teoría eran catecúmenos, pero en la práctica posponían el bautismo sine die, unas veces por miedo a romper los compromisos bautismales, otras por la comodidad de gozar de las ventajas de los cristianos pero sin someterse a las exigencias de los fieles. ${ }^{37}$ San Ambrosio se lamentaba de esta situación:

"Nadie se ha inscrito todavía, aún es noche para mí. Lo he avisado en la fiesta de Epifanía, y nada he recibido aún. He trabajado durante el día; espero tu orden, porque tú lo dices echaré las redes." (Tratado sobre el Evangelio de San Lucas 4,76).

34. Cf. Trad. Apost. 17-19. Es curioso que en la primera parte de este escrito dedicada a la construcción de la Iglesia (nn. 1-14) se haga mención de quienes tienen un lugar especial en la comunidad (obispo, presbíteros, diáconos, confesores, viudas, lectores, vírgenes, subdiáconos) pero no se diga ni una sola palabra respecto a los doctores que desempeñarán un papel importantísimo en el catecumenado.

35. "Pero, si alguno fuera celoso y aplicado en el cumplimiento de sus obligaciones, no se juzgará el tiempo, sino solamente su conducta" (Trad. Apost. 17).

36. "Esta institución tenía la finalidad de preparar en común a las personas adultas que habían manifestado la intención de convertirse al cristianismo, tanto para perfeccionar su conversión en el plano de la ortodoxia y de la ortopraxis como para la recepción de los sacramentos de la iniciación cristiana" G. Groppo, Catecumenado antiguo, 146.

37. Cf. SAn Agustín, Confesiones I, 17-18. Una de las razones de la decadencia del catecumenado hay que buscarla en esta prolongación cuasi indefinida del estado de catecumenado cf. L. RESINES, El catecumenado en "De catechizandis rudibus", 374; M. DUJARIER, Breve historia del catecumenado, 86-90; G. GROPPO, Catecumenado antiguo, 148. 
Las mejores catequesis bautismales y mistagógicas corresponden al período que va del siglo IV al VI, el número de bautizados aumenta, pero todo ello manifiesta la progresiva relajación respecto a los siglos precedentes. ${ }^{38}$ La estructura catecumenal se mantiene, pero cada vez hay menos convertidos. A pesar de todo, los obispos no dejarán de insistir en la necesidad de una auténtica conversión y fe para acceder al bautismo. El peligro de vaciar los ritos de su significado e implicaciones se extendía, por ello, los pastores no dejaron de llamar la atención sobre este punto. ${ }^{39}$

Si el catecumenado duraba -siguiendo el testimonio de Hipólito, tres años- después del Edicto de Milán el tiempo se va reduciendo progresivamente hasta prácticamente limitarse a la Cuaresma. ${ }^{40} \mathrm{El}$ rito del nomen dare, o inscripción del nombre de los aspirantes que deseaban recibir el bautismo en la próxima vigilia pascual, inauguraba el catecumenado al comienzo de la cuaresma ${ }^{41}$.

\section{c) Los sacramentos de iniciación cristiana}

La preparación próxima a los sacramentos de iniciación cristiana comenzaba, según el testimonio de Hipólito, con un segundo examen sobre la vida de los elegidos para recibir el bautismo: "¿Vivieron honestamente mientras eran catecúmenos? ¿Honraron a las viudas? ¿Visitaron a los enfermos? ¿Hicieron todo tipo de buenas obras?" (Trad. Apost. 20). Si los que fueron sus garantes en la primera presentación daban un informe positivo, los candidatos eran considerados elegidos para recibir los sacramentos de iniciación a los que se prepararían durante una semana ${ }^{42}$ escuchando el

38. Cf. M. DUJARIER, Breve historia del catecumenado, 132.

39. "Cuando existe un propósito sincero, hace que seas llamado; pero si sólo tienes dispuesto el cuerpo, pero estás ausente con la mente, perderás el tiempo. Al bautismo se acercó también en cierta ocasión Simón Mago, pero no se sintió iluminado: y realmente bañó su cuerpo en el agua, pero no dejó que el Espíritu iluminase su corazón; el cuerpo bajó a la piscina; pero el alma no quedó sepultada con Cristo ni resucitó juntamente con él. Pongo este caso como ejemplo para que tú no caigas" (SAN CirILo DE JeRuSAlén, Procat. 1-2). Cf. J. LÓPEZ SÁEZ, Catecumenado e inspiración catecumenal, 286.

40. Cf. M. Dujarier, Breve historia del catecumenado, 118; 132; G. G. Groppo, Catecumenado antiguo, 148.

41. Cf. San Ambrosio, De Sacr. 3,2,12-13; San Agustín, Confesiones IX, 14; SaN Agustín, Serm. 229, 1; M. DUJARIER, Breve historia del catecumenado, 104-111. El rito del nomen dare al comienzo de la cuaresma suponía, a partir del siglo IV, la preparación más intensa para recibir los sacramentos de iniciación, pero de hecho se convirtió en el comienzo del catecumenado cf. M. DUJARIER, Iniciación cristiana de los adultos, 98-101.

42. Cf. D. BOROBIO, Catecumenado, 134; M. DUJARIER, Iniciación cristiana de los adultos, 99; 118; E. Romero Pose, Catequesis en la época patrística, en V. $\mathrm{M}^{\mathrm{a}}$ Pedrosa et al., 
Evangelio, con la imposición diaria de las manos, ayuno, exorcismos, oraciones y el rito del epheta. ${ }^{43}$ A pesar del cambio que supusieron los edictos de Constantino y el de Teodosio, San Agustín afirma claramente:

"Algunos enseñan indiscretamente que todos deben ser admitidos al bautismo de la regeneración de nuestro Señor Jesucristo, aunque no quisieran cambiar su vida mala y torpe [...] incluso alardeando con descaro que quieren permanecer en ella. [...] Juzgan perverso y a destiempo enseñar primero cómo debe vivir un cristiano y después bautizarlo. Estiman que debe preceder el sacramento del bautismo a la enseñanza de la vida y costumbres que practicará después [...]"44.

Como vemos, la iniciación sacramental suponía una separación respecto de la vida y valores previos para poder insertarse como persona regenerada en la comunión cristiana. El obispo de Hipona no puede ser considerado como representante del ala extremista de la Iglesia respecto a la admisión al bautismo, pues se opone al rigorismo de los donatistas y, con sano realismo teológico-pastoral admite que en la misma Iglesia hay que saber tolerar la presencia de buenos y malos cristianos. ${ }^{45}$ Con todo, defiende la necesidad de una seria preparación y conversión de vida antes del bautismo ${ }^{46}$.

La traditio symboli y la traditio orationis eran, a partir de siglo IV, las entregas solemnes del Credo y del Padre Nuestro al final de las catequesis cuaresmales con las que los competentes realizaban la preparación próxima para recibir el bautismo. ${ }^{47}$ Las dos traditio eran la transmisión de dos puntos de referencia fundamentales de la fe y se presentaban como fórmulas-tipo.

Nuevo diccionario de catequética I, San Pablo, Madrid 1990, 366. Otros autores consideran que este periodo de preparación inmediata duraba toda la cuaresma cf. J. LÓPEZ SÁEZ, Catecumenado e inspiración catecumenal, en V. $\mathrm{M}^{\mathrm{a}}$ Pedrosa et al., Nuevo Diccionario de Catequética I, San Pablo, Madrid 1990, 285.

43. Cf. Trad. Apost. 20. "Así pues, ¿qué hicimos el sábado? La 'aperitio': Las ceremonias de la 'aperitio' se celebran cuando el sacerdote te toca los oídos y las narices. ¿Qué significan? [...recuerda el texto de Mc 7,4] Palabra hebrea [epheta] que quiere decir: 'ábrete'. El sacerdote por tanto te toca los oídos para que se te abran a la explicación y sermón del sacerdote." SAN AmBrosio, De Sacr. 1,1,2.

44. San Agustín, De fide et op. I, 1.

45. Cf. SAN AGuStín, De fide et op. IV, 6; XXVII, 49.

46. Cf. SAN Agustín, De fide et op. VI, 9; XXVII, 49.

47. Respecto a la duración de la catequesis (las semanas de cuaresma), su contenido (la Escritura y el credo), los ritos catecumenales del símbolo (traditio y redditio) que se desarrollaba en Jesuralén tenemos tanto el testimonio de su obispo Cirilo como de Egeria. Cf. EGERIA, Itiner. 46, 3-6. La liturgia de las entregas no aparece atestiguada hasta el siglo IV, aunque algunas obras de Tertuliano, Orígenes y Cipriano (s. III) son iniciaciones a la oración a partir del Padre Nuestro cf. M. DUJARIER, Iniciación cristiana de los adultos, 131; 135; 137. 
"[...] la recitación de memoria de la regula fidei como fórmula de la identidad cristiana es importante. Recitar el Credo no es sólo un acto de fe, decisión, entrega o compromiso. Es afirmación a la vez de un contenido preciso de la fe, de una realidad objetiva que se acoge y acepta a través de la fe de la Iglesia"48.

El Símbolo era el signo de que la fe cristiana es un todo orgánico que puede expresarse, por muy imperfectas que sean las palabras empleadas. La formulación de los diferentes credos depende, en la mayor parte de los casos, de las luchas y polémicas contra las distintas herejías. El Padrenuestro, por otra parte, es el signo de una fe que se hace palabra dirigida a Dios como alabanza y petición ${ }^{49}$. En Milán, San Ambrosio hacía la traditio orationis en las catequesis mistagógicas, mientras que en Hipona primero se entregaba el símbolo ${ }^{50}$ y una semana después el Padre Nuestro. La redditio symboli y la redditio orationis eran los ritos por los que los competentes recitaban de memoria el símbolo y la oración del Señor respectivamente ante la comunidad cristiana, salvo excepciones ${ }^{51}$.

Los sacramentos de iniciación cristiana, junto con los ritos que los acompañaban, tenían lugar durante la vigilia pascual: las renuncias a Satanás, ${ }^{52}$ la primera unción con el aceite de exorcismo, ${ }^{53}$ el bautismo por triple inmersión, ${ }^{54}$ la segunda unción con el aceite de acción de gracias, entrada en la iglesia, la imposición de manos, la unción del obispo con el aceite de acción de gracias, signación en la frente, el beso junto con el deseo de la paz del obispo y la participación en la eucaristía ${ }^{55}$. La recepción de los sacra-

48. M. MATos, La catequesis como Traditio evangelii in symbolo, en Actualidad catequética 106 (1982) 103.

49. Cf. J. Vernerre - H. Bourgeois, Perspectivas catecumenales. Un futuro para la fe, Marova, Madrid 1980, 143.

50. Cf. SAn Agustín, Serm. 56,1; 57,1; 58,1; 59,1.

51. Cf. San Agustín, Confesiones VIII, 5.

52. Cf. Trad. Apost. 21; San Ambrosio, De Myst. 2,5; 7; SAN Ambrosio, De Sacr. 1,2,5;8.

53. Cf. Trad. Apost. 21; SAN Ambrosio, De Sacr. 1,2,4.

"En el rito milanés hay una inversión respecto al rito romano. En este último, la renunciación es anterior a la unción con el óleo de los catecúmenos; aquí, en cambio, San Ambrosio atestigua que el catecúmeno era ungido antes de la renunciación, como si esta fuera un episodio de la lucha contra el demonio. Otra característica del rito que atestigua Ambrosio y que se ha mantenido en el rito ambrosiano es la fórmula binaria de la renunciación, cuando, en cambio la romana es ternaria." SAN AMBRosio, La iniciación cristiana. (La explicación del Símbolo, los Sacramentos, los Misterios), C. Basevi (ed.), Rialp, Madrid 1977,46 , nota 4.

54. Cf. Trad. Apost. 21; SAn Ambrosio, De Sacr. 2,6,16; 2,7,20; SAN Ambrosio, De Myst. 5,28.

55. Cf. Trad. Apost. 21. Según A. Kavanagh, la confirmación aparece como un evento de transición que hace de bisagra entre el bautismo (realizado en una relativa privacidad 
mentos constituía el punto culminante de la iniciación cristiana pues suponía la agregación del elegido a Cristo y como miembro pleno a la comunidad cristiana.

La fe cristiana puede ser considerada como una opción de vida de adhesión y seguimiento de Cristo lo cual implica una renuncia de otras posibilidades de vida que se oponen a dicho seguimiento. En el rito de la renuncias se trata de expresar la dinámica interior que se produce en el que ha escuchado la predicación de la Palabra y cree en ella. En esta dinámica hay un rechazo explícito de la situación anterior en la que la persona se encontraba antes de ser creyente. El rito de la renuncia es la expresión simbólicoritual -y por tanto externa- de la actitud interna de conversión. Mientras el Nuevo Testamento considera esta actitud de conversión como indispensable (cfr. Mc 1,4; Lc 3,3; Hch 2,38) para aceptación de la Buena Noticia, sin embargo, no demanda una forma concreta por la que esta actitud deba ser expresada simbólicamente. Desde muy pronto, el rito de la renuncia a Satanás entró a formar parte de la iniciación cristiana como símbolo de conversión junto con la profesión de adhesión a Cristo. Bajo este rito litúrgico se encuentra la experiencia central cristiana de 'llegar a creer'. La fe implica aquí un evento, un paso dinámico de una situación a otra, un cambio, una metanoia, una introducción en un nuevo mundo de conciencia, una inserción en la historia de salvación que asume el pasado, el presente y el futuro. Este drama de la iniciación cristiana es descrito de muchas maneras en el Nuevo Testamento, por ejemplo, en el encuentro entre Felipe y el eunuco etíope en el camino hacia Gaza (Hch 8, 26-40) o en la conversión de Saulo en el camino de Damasco (Hch 9,1-19). La renuncia a Satanás es explicada de forma tipológica por Cirilo recurriendo al relato de la salida de Egipto (Ex 14, 15-31) para pasar posteriormente a descubrir la centralidad de la liberación del pecado otorgada por Cristo (cf. Mistag. 1, 2-8). Uno de los hilos conductores en la interpretación de la fórmula de renuncia a Satanás y compromiso con Cristo es la presunción de que la persona que quiere convertirse a Cristo y comprometerse con Él entrando a su servicio es impedida para hacerlo por un antiguo contrato que la ata en una dura servidumbre. La persona no es responsable de este contrato, pero lo here$\mathrm{da}$; tampoco puede romper este contrato por sus solas fuerzas, pues su antiguo amo es demasiado poderoso. Para pasar de la esclavitud a la libertad no es suficiente un simple compromiso litúrgico-ritual con Cristo. La implica-

debido a la desnudez de los candidatos) y la eucaristía pública cf. A. KAVANAGH, Initiation: Baptism and Confirmation, en Worship 46 (1972) 273. 
ción de este compromiso conlleva entrar en una vida al servicio de Cristo, una nueva conciencia de su mundo hacia el que el catecúmeno está en camino de preparación para que, por este paso, se dé cuenta de los impedimentos -internos y externos-que impiden esta autodeterminación. Esta falta de libertad, particularmente en el entorno concreto del candidato es rechazada por medio de la fórmula verbal ("Renuncio a ti, Satanás, y a todas tus obras, y a toda tu pompa, y a todo tu culto") y del lenguaje corporal (movimiento de las manos, ${ }^{56}$ giro corporal del oeste al este, ${ }^{57}$ el pisotear determinados símbolos del pecado ${ }^{58}$ ) para entrar en la libertad de Cristo. El bautismo, mediante el rito de las renuncias, hace referencia a un cambio de señorío, un reconocimiento vivencial de que sólo Jesús es el Señor. Para romper la antigua esclavitud, el candidato no está sólo pues necesita la ayuda del poder de Cristo que le apoya en un momento tan decisivo. 59 Haciendo pues memoria del poder salvífico de Cristo, el candidato se une en su decisión personal al nuevo Señor para romper en el presente la antigua servidumbre que había heredado. La solemne expresión del nuevo compromiso ${ }^{60}$ es manifestación de la conversión interior y de un cambio de las relaciones interpersonales del candidato con los otros y con el mundo61.

56. Cf. SAn Cirilo de Jerusalén, Mistag. I, 2.4.

57. Cf. SAN Cirilo de Jerusalén, Mistag. I, 9.

58. "Se devuelve a la humildad lo que se negó a la soberbia. En el momento de los escrutinios, es cierto, y cuando el mismo inductor de la fuga y la deserción es debidamente increpado con la fuerza de la tremenda Trinidad, no estabais revestidos de cilicio, pero, no obstante, vuestros pies estaban místicamente firmes en él. Hay que pisotear los vicios y las pieles de cabra; hay que rasgar los trapos sacados de siniestros cabritos. El padre misericordioso saldrá a vuestro encuentro con el vestido originario, él que no dudó en inmolar el becerro cebado para que desapareciera vuestra pestífera hambre. Comed su carne, bebed su sangre [...]" SAN AGUSTín, Serm. 216, 10-11. Este texto hace mención de un exorcismo cuaresmal que consistía en ponerse de pie sobre una piel de cabra. Para Agustín, la piel de cabra es símbolo de los pecados a los que renuncian los catecúmenos cf. SAN AGUSTín, Obras completas XXIV, BAC, Madrid 1983, 794, nota 16; W. HARMLESS, Augustine and the Catechumenate, 263. Un rito parecido debía existir en Milán, pero en este caso los catecúmenos "apoyaban sus pies desnudos sobre un cilicio de tela, símbolo del hombre viejo que el cristiano debe deponer y pisotear." SAN AMBROSIO, La iniciación cristiana. (La explicación del Símbolo, los Sacramentos, los Misterios), edición de C. Basevi (ed.), Rialp, Madrid 1977, 23, nota 1. Sobre los escrutinios y exorcismos en el catecumenado de los siglos IV al VI cf. M. DUJARIER, Iniciación cristiana de los adultos, 120-122.

59. "Renuncio a ti, Satanás, a ti que eres tirano maligno y muy cruel. Ya no temo -dijiste- tu fuerza: Cristo la deshace haciéndome partícipe de su sangre y de su carne para, por ellas, destruir la muerte con su nombre para que no esté sometido eternamente a esclavitud." (SAn Cirilo de Jerusalén, Mistag. I, 4).

60. "Creo en el Padre, y en el Hijo y en el Espíritu Santo, y en un único bautismo de conversión." (SAN CirILo de Jerusalén, Mistag. I, 9).

61. Cf. San Agustín, Confesiones VIII,12. 
No se trata de fórmulas y gestos muertos, sino de expresiones de lo que ya se ha debido ir produciendo previamente en la vida entera del candidato de forma real. En este acto se expresa lo real del cambio de vida en forma ritual. Por ello, si se vacía lo ritual de lo real se convierte en fórmula muerta vaciada de todo sentido y eficacia. La ayuda de Cristo a la hora de romper el antiguo pacto es ineficaz si no viene en ayuda de una decisión de romper tal vínculo. La adhesión de fe está vacía si no existe la relación interpersonal que antes hemos comentado.

Los ritos de agregación llevados a cabo en la vigilia pascual varían de unas iglesias a otras y a lo largo de los siglos, pero el que permanece constante es el bautismo propiamente dicho y, a continuación, la participación en la eucaristía. La participación en el Cuerpo de Cristo pone de manifiesto que el 'paso' se ha consumado. La comunión eucarística es el rito de agregación por excelencia pues manifiesta que el neófito forma parte de la expresión máxima de la comunidad.

\section{d) Etapa mistagógica}

Ser acogido y acoger, superar las antiguas servidumbres y escapar a determinadas alienaciones para entrar en una relación más estrecha con Cristo: esta es la dinámica que está bajo toda la dinámica de la iniciación cristiana. La libertad cristiana se mide no sólo por la esclavitud de que la iniciación separa sino también por la comunión en la que introduce. Para asegurar plenamente la inserción del neófito en la comunidad que le acoge, participa durante el tiempo pascual en unas catequesis especiales que, a diferencia de las catequesis previas, desvelan los misterios en los que el nuevo miembro ha sido iniciado. Las catequesis mistagógicas intentan que el neófito -la nueva planta- pueda injertarse sólidamente en la vida de la comunidad cristiana que es el Cuerpo de Cristo. La mistagogia es, pues, la instrucción impartida para ayudar a los candidatos a entender el significado de lo que se dijo e hizo en la liturgia de su iniciación en la vida cristiana; es la instrucción en el significado de los misterios o sacramentos. ${ }^{62}$ La función pastoral de la mistagogia era hacer de puente entre los sacramentos celebrados, su significado y su proyección hacia el resto de la vida cristiana. La mistagogia es la catequesis propia que trata de llevar a plenitud la agrega-

62. Cf. H. M. RILEY, Christian Initiation. A Comparative Study of the Interpretation of the Baptismal Liturgy in the Mystagogical Writings of Cyril of Jerusalem, John Chrysostom, Theodore of Mopsuestia and Ambrose of Milan, The Catholic University of America Press, Washington D.C. 19742. 
ción al misterio de Cristo y de la comunidad cristiana que se ha llevado a cabo de manera sacramental.

No tenemos constancia documental de que durante los tres primeros siglos de la Iglesia existiera una etapa mistagógica con actos propios destinados a los neófitos. Con el declinar del catecumenado en el siglo IV, se sintió la necesidad de prolongar la formación de los que habían sido iniciados sacramentalmente. Durante una semana ('in albis'), los neófitos eran los destinatarios de unas catequesis especiales para ayudarles a profundizar en los misterios (sacramentos) de los que habían participado y a vivir de acuerdo a la nueva condición ${ }^{63}$.

\section{2.- Elementos de la liminaridad catecumenal}

El catecumenado, como etapa liminar de la iniciación cristiana, fue de vital importancia en el proceso de iniciación cristiana descrito por Hipólito. El catecumenado, en su estricto sentido, tenía un antes y un después: el antes lo determina la acción evangelizadora de la Iglesia por la que despierta un primer interés por el mensaje del Evangelio y una primera conversión hacia Él. La fase que sigue al catecumenado ha de ser la agregación del neófito a la comunidad cristiana de cuya vida previamente no participaba en plenitud.

A continuación vamos a centrarnos en algunas características -negativas y positivas-propias del catecumenado clásico que anteriormente hemos detectado en la fase liminar de los ritos de iniciación. El catecumenado es, según los testimonios patrísticos, un 'tiempo ambiguo' al ser, en el sentido que le da Victor Turner, un tiempo 'anti-estructural'.

\section{a) Aspectos negativos de la liminaridad catecumenal}

El catecumenado, como intervalo e institución eclesial, pone de manifiesto unos aspectos que podemos llamar 'negativos'. Como institución, el catecumenado es, en el sentido sociológico del término, una etapa 'antiestructural': las relaciones, valores y normas que hasta entonces estaban vigentes son suspendidas y reemplazadas por otras. El catecumenado antiguo era, en este sentido, una especie de institución 'contracultural' frente al ámbito del que proviene el candidato.

63. Cf. M. DuJARIER, Iniciación cristiana de los adultos, 189-198. 


\section{a. 1.- Invisibilidad}

La invisibilidad estructural del catecúmeno comienza, propiamente cuando es aceptado para comenzar el catecumenado. Se simboliza con el primer examen mediante el cual la comunidad constata, mediante indicios externos, que se ha producido en el candidato la conversión inicial. Esta invisibilidad estructural hace referencia a que ya no está en el ámbito y lugar que ocupaba en la fase anterior como 'pagano', pero todavía no está en la posición que ocupará al final de la iniciación como 'fiel'. La invisibilidad de los catecúmenos se ponía de manifiesto al formar un 'orden' especial dentro de la asamblea litúrgica. Según Hipólito, al finalizar cada catequesis, los catecúmenos oraban separados de los fieles ${ }^{64}$ señalando así su no-pertenencia a la comunidad de los fieles. Por otra parte, terminada la 'misa de los catecúmenos' (hoy liturgia de la Palabra) salían del templo. San Agustín, para explicar de manera simbólica el sentido del catecumenado comparaba a los que pertenecían a este orden con los granos de trigo que, sin existir, fueron 'creados' y 'llevados', es decir, apartados, por la predicación del Evangelio. Y continúa diciendo: "Mientras permanecisteis en el catecumenado estabais como guardados en el granero; cuando disteis vuestros nombres comenzasteis a ser molidos con el ayuno y los exorcismos"65. El catecumenado es, por tanto, el ámbito donde los catecúmenos son 'colocados aparte' para que su estado previo sea triturado o demolido y posibilitar, más tarde, la regeneración al modo de vida propio de los creyentes en Jesucristo. Durante el catecumenado se trataba de dar muerte al 'hombre viejo' y por tanto la invisibilidad estructural formaba parte de su condición. Al mismo tiempo, el catecumenado es lugar de gestación, comparado con el seno materno donde se está gestando, de manera invisible, a nuevos cristianos: "Se les daba el nombre de competentes porque con su petición sacu-dían las entrañas maternas para nacer [...]"66.

\section{a. 2.- Impureza}

El catecúmeno, al estar colocado en la fase liminar, llevaba una vida estructuralmente ambigua y todavía no totalmente definida. Debía ser colocado aparte para preservar la vida comunitaria ya estructurada respecto a las referencias fundamentales de la identidad cristiana. La vida de los catecúmenos estaba, al mismo tiempo, desestructurada y pre-estructurada y, por

64. Cf. Trad. Apost. 18.

65. SAn Agustín, Serm. 229, 1.

66. SAn Agustín, Serm. 228, 1. 
tanto, no podían compartir completamente la misma vida de los fieles. Cuando terminaba la catequesis los catecúmenos -como ya hemos dichooraban separados de los fieles laicos y, al final de la plegaria, no se daban el beso de la paz "puesto que su beso no es santo aún" (Trad. Apost. 18). El catecumenado, como etapa destinada a conseguir la estructuración del destinatario conforme a los referentes de identidad cristiana, tenía dos ritos clásicos con este fin: uno miraba a las estructuración 'exterior' -los escrutinios- y otro a la estructuración 'interior' -los exorcismos-. Aunque esta división no debe ser considerada de manera excesivamente rígida, hace referencia tanto a la acción humana como a la divina ${ }^{67}$.

"Hasta ahora hemos celebrado los misterios de los escrutinios. Se nos ha hecho preguntas para que no haya ninguna inmundicia en nuestro cuerpo. Los exorcismos, en cambio, iban dirigidos y han conseguido la santificación no sólo de nuestro cuerpo, sino también de nuestra alma"68.

\section{a. 3.- Pobreza}

En el catecumenado, el objetivo es renacer a la nueva vida en Cristo pues la antigua ha sido empobrecida y degradada por el pecado. Ser conscientes de esta situación era necesario para valorar la iniciación y apreciar nueva vida a la que los candidatos iban a ser introducidos. Negar la realidad del pecado imposibilitaba para recibir la salvación de Cristo ${ }^{69}$. Ningún catecúmeno podía, por tanto, presumir de ningún título o posesión previa pues

67. Cf. San Agustín, Serm. 216, 10-11. Estos ritos están encaminados a expresar el "conflicto que se debate en el corazón del convertido entre Cristo y Satán. Este trata de cerrar el camino que va hacia Dios y de retener al catecúmeno en sus redes. Todos estos ejercicios de Cuaresma [oraciones, ayunos, insuflaciones, lecturas bíblicas, exorcismos] tienen por objeto desasir progresivamente el alma del dominio que el demonio opera sobre ella." M. DUJARIER, Iniciación cristiana de los adultos, 121. La cosmovisión de la antigüedad, en la que las fuerzas demoníacas eran las responsables de todos los desastres y calamidades, modeló la concepción cristiana de la conversión. Algunas veces, se hablaba de la conversión en términos semejantes a los empleados por nosotros, pero otras consideraban la conversión en términos cosmológicos de ahí la importancia que tenían las prácticas cuaresmales en términos de lucha contras las fuerzas de las tinieblas cf. W. HARMLESS, Augustine and the Catechumenate, 260-265.

68. SAN Ambrosio, Expl. Symb. 1. "Solamente hacia el final del siglo IV la palabra escrutinio (scrutinium) aparece en Ambrosio. En aquel momento, en efecto, en razón de la afluencia de catecúmenos y del carácter precario de su conversión, la Iglesia tuvo que organizar exorcismos creando los escrutinios de Cuaresma." M. DUJARIER, Iniciación cristiana de los adultos, 117. Los exorcismos están atestiguados desde mucho tiempo antes en la Tradición Apostólica.

69. Cf. San Ambrosio, De Sacr. 3,2,12-13. 
su condición común era compartir la pobreza radical del pecado de la que ninguno podía salir por sus propios medios ${ }^{70}$.

\section{b) Aspectos positivos de la liminaridad catecumenal}

\section{b.1.- Gestación}

Remite a la clásica imagen de la Iglesia como Madre. Su origen, antes que mariológica, se enraíza en la misión evangelizadora de la misma Iglesia. Los destinatarios de la misión son hechos hijos de Dios por mediación de la Iglesia en su función maternal. ${ }^{71} \mathrm{El}$ proceso y la estructura iniciática de la Iglesia estaba durante los primeros siglos en el centro de su ser y su obrar:

“¿Qué tienen que hacer [los catecúmenos] para que se les confíe Jesús? Renacer del agua y del Espíritu Santo; que la Iglesia dé a luz a los que lleva en sus entrañas. Salgan a la luz después de ser concebidos. Habrá pechos que los alimenten y no teman sofocarse en naciendo; no se alejen de los pechos maternos"72.

La Iglesia no sólo debía gestar y dar a luz a nuevos miembros de Cristo sino que también tenía que mantener esa vida incipiente arropando a los neófitos con el ejemplo de una vida coherente en todos los que ya son, o deben ser, fieles.

"De estos días, los siete u ocho en que nos encontramos se dedican a los sacramentos que han recibido los recién nacidos. Los que hasta hace poco recibían el nombre de competentes, ahora se llaman infantes. Se les daba el nombre de competentes porque con su petición sacudían las entrañas maternas para nacer; se les llama infantes porque acaban de nacer para Cristo los que antes habían nacido para el mundo. Ha nacido en ellos la vida, que en vosotros debe de tener ya sólidas raíces. Los que sois fieles ya, dadles ejemplo; pero no ejemplos que les conduzcan a la muerte, sino ejemplos que les sean de provecho.

70. Los elegidos no podían llevar nada a la vigilia pascual en la que iban a ser bautizados, excepto la ofrenda para la eucaristía. En el momento de ser introducidos en el agua para ser bautizados no podían llevar ningún objeto extraño como por ejemplo las joyas cf. Trad. Apost. 20-21.

71. "Mi sermón se dirige a vosotros, niños recién nacidos, pequeños en Cristo, nuevo retoño de la Iglesia, gracia del Padre, fecundidad de la madre [...]" SAN AGusTín, Serm. 260 A, 1. "No puede tener a Dios por Padre quien no tiene a la Iglesia por Madre." SAN Ambrosio, Expl. Symb. 4, 13. Cf. M. DuJARIER, Breve historia del catecumenado, 119-120; M. DUJARIER, Iniciación cristiana de los adultos, 76-77.

72. San Agustín, In Joh. 12,3. 
Los que acaban de nacer ponen sus ojos en cómo vivís vosotros, los nacidos antes" 73 .

\section{b. 2.- 'Estructura social' de la liminaridad catecumenal}

Las relaciones de los catecúmenos con sus iniciadores y de los catecúmenos entre sí eran las que normalmente se establecen en cualquier tipo de iniciación en una sociedad tradicional. Por una parte, el sometimiento a la autoridad de los maestros (también llamados doctores audientium) y, por otra, la igualdad entre los catecúmenos son las características más destacables. Mientras que en la comunidad cristiana puede haber, propiamente hablando, una estructura social mucho más compleja, en el catecumenado 'sólo' hay dos posiciones posibles: maestro o discípulo.

En el catecumenado, por su misma definición, se trataba de hacer resonar la palabra de Dios para que el catecúmeno afianzase y llevase a madurez su primera conversión. La catequesis, independientemente de todas las discusiones que en torno a ella se puedan establecer, necesita siempre un 'testigo' que anuncie explícitamente la Buena Noticia. Ese testigo, como miembro de la comunidad cristiana, transmite un mensaje que no es de su invención ni de la comunidad a la que pertenece sino que ha sido recibido y aceptado desde la fe. Por esta razón, la autoridad del iniciador no descansaba sobre símismo sino sobre el mensaje a transmitir: el Evangelio.

"No hablo de cosas peregrinas ni voy a búsqueda de lo absurdo, sino, discípulo que he sido de los Apóstoles, me convierto en maestro de las naciones: yo no hago sino transmitir lo que me ha sido entregado a quienes se han hecho discípulos dignos de la verdad. [...] Si no contristas esta gracia, conocerás lo

73. San Agustín, Serm. 228, 1. "Y lo que sigue nos pertenece ya a nosotros. En la santa Iglesia. Nosotros somos la santa Iglesia; pero no dije 'nosotros', como si me refiriese sólo a los que estamos aquí, a quienes ahora me oís, sino a cuantos por la gracia de Dios somos fieles cristianos en esta Iglesia, es decir, en esta ciudad; cuantos hay en esta región, en esta provincia, cuantos hay al otro lado del mar y en todo el orbe de la tierra [...] ¡Honrémosla porque es Señora de tan gran Señor! ¡Grande y particular la misericordia del esposo para con ella! La encontró meretriz, y la hizo virgen. No debe olvidar que fue meretriz, para no olvidar la misericordia de su libertador. [...] La Iglesia es virgen. Tal vez me dirás: 'Si es virgen, ¿cómo da a luz hijos? O, si no alumbra hijos, ¿cómo es que hemos dado nuestros nombres para nacer de sus entrañas?' Respondo: 'Es virgen y da a luz; imita a María, que dio a luz al Señor.' ¿Acaso Santa María no dio a luz siendo virgen y permaneció siéndolo? Así la Iglesia: da a luz y es virgen; y, si lo piensas atentamente, da a luz a Cristo, puesto que los bautizados son miembros suyos. Dice el Apóstol: Vosotros sois el cuerpo de Cristo y sus miembros. Si, pues, alumbra los miembros de Cristo, la semejanza con María es grandísima." SAN Agustín, Serm. 213, 8. 
que el Verbo habla por medio de quienes quiere y cuando quiere. $\mathrm{Y}$, en efecto, cuantas cosas fuimos movidos a explicaros con celo por voluntad del Verbo que nos las inspira, os las comunicamos por amor de las mismas cosas que nos han sido reveladas"74.

La obediencia que el catecúmeno debe al catequista estaba en función, por una parte, de Dios mismo como fuente de la revelación y, por otra, en función del mensaje que no podía ser inventado por los que son iniciados. En el caso de la catequesis, la fuente del mensaje y el mensaje mismo coinciden, pues no se trata de un conjunto de verdades abstractas sino del misterio de Dios revelado por Jesucristo: revelación y revelador coinciden. Esta es la razón por la que la autoridad de los 'maestros' de la iniciación cristiana no es absoluta en sí misma sino que depende del sometimiento de éstos a la autoridad del 'único Maestro'75.

"Hijo mío, noche y día te acordarás del que te anuncia la palabra de Dios y lo honrarás como al Señor, pues donde se proclama su soberanía, allí está el Señor. Buscarás cada día la presencia de los santos para descansar en sus palabras"76.

En la medida en que los iniciadores se sometan a la autoridad del único Maestro y sean obedientes a su voluntad así podrán desempeñar su misión y solicitar de sus destinatarios el obsequium fidei sin que se produzcan rupturas y crisis de sentido.

En la fase del catecumenado, todos los que estaban siendo iniciados participaban de una igualdad básica. Las diferencias de estatus que en su vida pasada les distanciaban eran anuladas porque las estructuras previas habían sido eliminadas en función de la iniciación que pretendían alcanzar.

"Vuestro mismo nombre, el hecho de que se os llame competentes, manifiesta que eso es lo que deseáis, que eso ambicionáis con toda la fuerza de vuestra mente. ¿Qué otra cosa significa el término competentes sino que piden conjuntamente? Lo mismo que co-docentes, con-currentes, co-sedentes, no significan otra cosa sino que enseñan, corren y se sientan al mismo tiempo, del mismo modo la composición de la palabra competente indica a quienes piden y desean una misma cosa a la vez. ¿Y qué es esa única cosa que pedís y deseáis sino aquello por lo que clama cierto hombre intrépido que ya había depuesto los deseos carnales y vencido los temores mundanos?"77.

74. Discurso a Diogneto XI, 1.7-8.

75. Cf. SAN Agustín, De cat. rud. VII,11.

76. Didaché IV, 1-2. La cursiva es muestra. Para la misma idea cf. Ps-Bern. XIX, 9.

77. San Agustín, Serm. 216, 1. 
En el orden o grupo de los catecúmenos todos forman una especie de 'comunidad aparte' en la que las diferencias jerárquicas han sido abolidas porque todos comparten un mismo camino donde sus deseos y destinos están fusionados. La unión profunda que se establece en el mismo 'condiscipulado' trata de crear lazos profundos que les aúnen en vistas a la comunión de la que van a formar parte. De esta manera, el catecumenado es anticipo y escuela de la comunión a la que entrarán a formar parte. El grupo de iniciandos es una piña de 'compañeros' que anticipa y prepara para la autentica compañía eclesial de los que 'comen el mismo pan' (= cum-panis).

\section{b. 3.- Comunicación del Misterio cristiano}

Al participar activamente, por medio de los signos visibles que constituyen la liturgia propia de la iniciación catecumenal, el candidato era ayudado para que descubriera significativa y experiencialmente la historia de la salvación como relato en el que insertarse vitalmente. Esto se hacía no sólo con una instrucción verbal (catequesis) sino también a través de una participación activa y concreta en acciones físicas que el candidato realizaba para pasar simbólicamente de un mundo visible a otro invisible. En estos ritos de paso el mundo conocido por la experiencia del catecúmeno no era destruido sino iluminado en profundidad para ser iniciado en el significado de su propia vida a la luz del plan salvífico de Dios. Pasar por la iniciación simbólica cristiana suponía para el neófito volver a su misma existencia para vivirla, a partir de ese momento, en un nivel más profundo de entendimiento en la compañía de Dios y de la comunidad. El neófito accedía a estos nuevos compañeros de camino por mediación de la liturgia cristiana de iniciación ${ }^{78}$.

La comunicación del misterio cristiano se llevaba a cabo mediante la catequesis y se condensaba en el Símbolo ${ }^{79}$. Su entrega era una catequesis-

78. Cf. H. M. RILEY, Christian Initiation. A Comparative Study of the Interpretation of the Baptismal Liturgy in the Mystagogical Writings of Cyril of Jerusalem, John Chrysostom, Theodore of Mopsuestia and Ambrose of Milan, 1-2.

79. "El símbolo constituye en vosotros lo que debéis creer y confesar para poder alcanzar la salvación. Lo que dentro de poco vais a recibir, confiar a la memoria y proferir verbalmente, no es novedad alguna para vosotros o cosa jamás oída. En efecto, en variedad de formas soléis oírlo tanto en la Sagrada Escritura como en los sermones de la Iglesia. No obstante eso, se os ha de entregar todo junto, brevemente resumido y lógicamente ordenado para edificar vuestra fe, facilitar la recitación y no cargar demasiado a la memoria. Estas son las cosas que, sin cambiar nada, habéis de retener y luego recitar de memoria." SAN AGustín, Serm. 214, 1. "El símbolo es, pues, la regla de fe, compendiada en pocas palabras 
rito que se llevaba a cabo con los catecúmenos que habían sido considerados dignos de recibir los sacramentos de iniciación. En los días previos a la Pascua, se realizaban muchos ritos que preparaban de manera inmediata la agregación de los iniciandos a la comunidad cristiana.

"Es ya tiempo de que recibáis el símbolo, que contiene, de forma breve, todo lo que creéis para vuestra salvación eterna. [...] Creedlo para comprenderlo; pues, si no lo creéis, no lo comprenderéis. Estando en posesión de esa fe, esperad la gracia, mediante la cual se os perdonarán todos los pecados. De ella os vendrá la salvación, no de vosotros mismos: es un don de Dios" ${ }^{\text {" }}$.

También se comunicaba el misterio cristiano por medio de la oración. La entrega del Padre Nuestro era otra de las catequesis-rito de agregación a la comunidad cristiana. Al competente se le entrega la oración común a todos los cristianos y que es parte integrante de su identidad como tales.

Ya hemos dicho que la redditio symboli y la redditio orationis consistían en que los competentes recitaban de memoria el símbolo y la oración dominical ante la comunidad cristiana ${ }^{81}$. Parece que había más de una redditio symboli: al menos una antes de Pascua (su datación y número varía de unos estudiosos a otros) y otra solemne en la vigilia pascual cuando se estaban celebrando los sacramentos de iniciación ${ }^{82}$. Las dos traditio son la transmisión de dos puntos de referencia fundamentales de la fe la lex credendi y la lex orandi-y se presentan como fórmulas-tipo.

Puesto que la comunicación del misterio cristiano se va haciendo más densa a medida que los catecúmenos se acercan a los sacramentos de iniciación cristiana se les exige que guarden en secreto los símbolos más apre-

mucho lo que se adquiere con ella. Se llama símbolo a aquello en que se reconocen los cristianos [...]" SAN Agustín, Serm. 213, 2. Cf. SAN Agustín, Serm. 212,1; 214, 12. El Símbolo no era solamente un conjunto de proposiciones a las que la persona asentía, también estaba destinado a modelar la conducta y a la unión con la comunidad cf. W. HARMLESs, Augustine and the Catechumenate, 278.

San Agustín, Serm. 212, 1; cf. SAn Agustín, Serm. 214, 10.

[COMMENT0]

***** La traditio symboli y la traditio orationis eran las entregas solemnes. Agustín de Hipona entregaba primero el símbolo cf. SAN AGUSTín, Serm. 56,1; 57,1;58,1;59,1) y una semana después el Padre Nuestro. San Ambrosio hacía la traditio orationis en las catequesis mistagógicas de pascua cf. De Sacr. 6,5,26.

80. Cf. San Agustín, Confesiones VIII, 5.

81. Cf. SAn Agustín, Obras completas XXIV, BAC, Madrid 1983, 792, nota 14. La primera redditio symboli tenía lugar una semana después de la traditio symboli. "Dentro de ocho días tendréis que recitar esto que hoy habéis recibido." SAN AgUSTín, Serm. 215, 1. 82. SAN AmBrosio, Expl. Symb. 9. 
ciados por la comunidad cristiana para que no sean transmitidos a infieles o a los que todavía no están iniciados:

"Os quiero dar un aviso: tened presente que este Símbolo no debe escribirse. Debéis repetirlo de memoria, pero sin que nadie lo escriba. ¿Por qué? Porque así nos han advertido: que no debe escribirse. ¿Qué hacer entonces? Aprenderlo. [...] En tu interior, sobre todo medítalo en tu interior. ¿Por qué? Para que no lo repitas por distracción en voz alta, donde hay catecúmenos o herejes, por haberte acostumbrado a decirlo fuerte para ti solo cuando estás entre los fieles" 83 .

En el catecumenado clásico la disciplina del arcano se aplicaba también a los sacramentos de iniciación. De ellos no se comentaba nada, ni siquiera a los que los iban a recibir. Esa era una de las funciones específicas de las catequesis mistagógicas. ${ }^{84}$ Esta disciplina del arcano, típica en muchas iniciaciones, predisponía al iniciado a captar la significación profunda de los ritos a los que se ha sometido.

"Cuando llegan los días de Pascua, durante aquellos ocho días, es decir, desde Pascua hasta su octava, una vez hecha la despedida de la iglesia, se va con himnos a la Anástasis; luego se hace oración, son bendecidos los fieles, y el obispo, de pie, apoyándose en el cancel interior que está en la gruta de la Anástasis, va exponiendo todo lo que se hace en el bautismo. Durante ese tiempo, ningún catecúmeno se acerca a la Anástasis: sólo los neófitos y los fieles [neofiti et fideles] que quieren oír los misterios [qui uolunt audire misteria] entran en la Anástasis ${ }^{85}$. Ciérranse las puertas, para que ningún catecú-

83. "Devuelto [reddito] el símbolo al obispo, éste habla a todos, diciendo: 'Durante siete semanas habéis sido instruidos en toda la ley de las Escrituras, y también se os ha hablado de la fe; habéis oído de la resurrección de la carne, como asimismo de todo el contenido del símbolo, como lo habéis podido oír siendo catecúmenos; pero en cuanto a los misterios más altos [misterii altioris], es decir, al bautismo mismo, no podéis oírlo, por ser todavía catecúmenos. Y no debéis creer que esto se haga sin razón; cuando en el nombre de Dios seréis bautizados, lo oiréis durante los ocho días de Pascua después de hecha la despedida en la Anástasis; porque siendo todavía catecúmenos, los misterios más secretos de Dios [misteria Dei secretiora] no pueden decírselos'." (EGERIA, Itiner. 46, 6]

84. "Las mistagógicas que se tienen todos los días, es decir, estas enseñanzas que explican los misterios, nos son útiles, pues siempre explican nuevas doctrinas y nuevas cosas. Pero os son útiles sobre todo a vosotros, que habéis sido cambiados de lo viejo a lo nuevo. En esta línea os expondré ciertas cosas que se derivan de la mistagogia de ayer, para que aprendáis qué simboliza lo que realizasteis en el interior del edificio" (SAN CIRILO DE JERUSALÉN, Mistag. II, 1).

85. EGERIA, Itiner. 47, 1-2. "Ahora ha llegado el momento de tratar acerca de los misterios y manifestar la razón última de los sacramentos; porque si hubiésemos explicado esto antes del Bautismo a los que todavía no estabais iniciados, hubiera parecido una traición más que una transmisión. Además penetra más en los principiantes la luz de los misterios 
meno vaya allí. Mientras el obispo expone y narra cada cosa, son tales los gritos de los que aclaman, que sus voces se oyen aun fuera de la iglesia. Porque en verdad expone todos los misterios de tal manera, que nadie puede menos de conmoverse al oír lo que tan bien expone" 86 .

Al ser una 'tradición', los sacramentos debían de permanecer ocultos para los que no habían sido iniciados en ellos y, de esta manera, no podían ser violados por una conducta indigna. Se trata de un pudor metafísico ${ }^{87}$. Por otra parte, la disciplina del arcano en la iniciación cristiana se justificaba también por la dinámica interna de la propia fe: primero es creer y luego la iluminación de esa fe.

Como hemos ido viendo, algunas de las características propias y más significativas de la fase liminar en otro tipo de iniciaciones, también las podemos encontrar en el catecumenado clásico. En él descubrimos la solidaridad estructural de las iniciaciones.

Manuel BerJón Martínez, OSA

Iquitos (Perú)

por sí sola que si está acompañada por una explicación prematura." (SAN AMBROSIO, De Myst. 1,2).

86. "[...] el misterio debe permanecer sellado en tu mente, a fin de que no sea violado por las obras de la mala vida [...]; a fin de que no sea divulgado a aquellos que no conviene; a fin de que no pare en manos de pérfidos a causa de la palabrería vana. Luego tu fe debe tener una buena custodia, a fin de que la integridad de vida y la guarda del silencio permanezcan intactos. Por eso la Iglesia guarda celosamente la profundidad de los misterios celestiales [...]. Porque posee buenos árboles y que dan buenos frutos; árboles que bañan sus raíces en el caudal de la fuente sagrada y que gracias al vigor de una nueva fecundidad se llenan de frutos buenos; así ya no serán cortados por la segur profética, sino estarán fundamentados en la fecundidad evangélica." (SAN AMBrosio, De Myst. 9, 55-56).

87. "Voy a tratar ahora de los sacramentos que habéis recibido, cuya razón no convenía explicar antes, porque en el hombre cristiano lo primero es la fe." (SAN AmBrosio, De Sacr. 1,1,1). "Considera tú también los ojos de tu corazón. Hasta ahora veías las cosas materiales con los ojos del cuerpo, pero las cosas sacramentales no las podías ver con los ojos del corazón." (SAN Ambrosio, De Sacr. 3,2,12). "Dice, en efecto, el profeta: Si no creéis, no comprenderéis [Is 7,9]. Ahora podéis decirme a mí: 'Nos mandas que lo creamos; explícanoslo para que lo entendamos.' [...] A estas cosas, hermanos míos, las llamamos sacramentos, porque en ellas es una cosa la que se ve y otra la que se entiende. Lo que se ve tiene forma corporal; lo que se entiende posee fruto espiritual." (SAN AGUSTín, Serm. 272). Cf. M. DUJARIER, Iniciación cristiana de los adultos, 197-198. 